Article

\title{
Undergraduate Research Involving Deaf and Hard-of-Hearing Students in Interdisciplinary Science Projects
}

\section{Todd Pagano ${ }^{1, *}$, Annemarie Ross ${ }^{1}$ and Susan B. Smith ${ }^{2}$}

1 Department of Science and Mathematics/Laboratory Science Technology Program, Rochester Institute of Technology, Rochester, NY 14623, USA; E-Mail: adrnts@rit.edu

2 Thomas H. Gosnell School of Life Sciences, Rochester Institute of Technology, Rochester, NY 14623, USA; E-Mail: sbssbi@rit.edu

* Author to whom correspondence should be addressed; E-Mail: tepnts@rit.edu; Tel.: +1-585-475-4539.

Academic Editor: John Blewitt

Received: 30 March 2015 / Accepted: 13 May 2015 / Published: 21 May 2015

\begin{abstract}
Scientific undergraduate research in higher education often yields positive outcomes for student and faculty member participants alike, with underrepresented students often showing even more substantial gains (academic, professional, and personal) as a result of the experience. Significant success can be realized when involving deaf and hard-of-hearing (d/hh) undergraduate students, who are also vastly underrepresented in the sciences, in interdisciplinary research projects. Even d/hh Associate degree level students and those in the first two years of their postsecondary careers can contribute to, and benefit from, the research process when faculty mentors properly plan/design projects. We discuss strategies, including the dissemination/communication of research results, for involving these students in research groups with different communication dynamics and share both findings of our research program and examples of successful chemical and biological research projects that have involved $\mathrm{d} / \mathrm{hh}$ undergraduate students. We hope to stimulate a renewed interest in encouraging diversity and involving students with disabilities into higher education research experiences globally and across multiple scientific disciplines, thus strengthening the education and career pipeline of these students.
\end{abstract}


Keywords: undergraduate research; underrepresented students; students with disabilities; deaf and hard-of-hearing; Associate degree level; early undergraduates; chemical and biological sciences

\section{Introduction}

Scientific research in higher education involves experimental or theoretical explorations that broaden knowledge, investigate the unknown, and/or attempt to answer real-world questions of science. Sometimes, scientific research with undergraduate students (or "undergraduate research") is thought to be a lower or "watered-down" form of research. But in reality, undergraduate research has no lesser fundamental goals, seeks the same knowledge, and attempts to answer the same scientific questions; only it does so with students who are in the early stage of their postsecondary education. Undergraduate research in an academic setting should therefore have several central objectives. It should (1) provide substantial student learning opportunities; (2) contribute in innovative and creative ways to the scholarship of the field; and (3) communicate findings/technical results. Students are not only central to the importance of performing this scholarship; they should be the catalyst, vehicle, and inspiration to the running of any academic research program. The synergistic outcome of these studentcentered efforts allows students to conduct original investigations that help to promote student learning while contributing to the scholarship of the discipline [1,2]. The current global momentum of undergraduate research in higher education is pronounced and many postsecondary institutions are actively promoting and expanding their undergraduate research programs.

In part due to student attrition in the field, the relatively low number of higher education graduates that are capable of filling critical STEM roles in the U.S. labor pool has been of concern, as shortages of skilled workers in certain scientific fields will impede our ability to remain globally competitive [3]. For a comparison of STEM education initiatives worldwide, readers are encouraged to refer to the comprehensive review by Marginson et al. [4]. Of further concern is the lack of diversity in the STEM fields [5], making the current emphasis on broadening participation in undergraduate research programs for underrepresented students in science especially exciting (the programs at Arkansas State University [6] and New Mexico State University/Fred Hutchinson Cancer Research Center [7] are but two such exemplary programs). Even though research participation by undergraduate students often results in positive outcomes for all students, Lopatto showed that those from underrepresented groups often show greater learning gains as a result of the experience [8].

Students with disabilities who are obtaining advanced degrees and progressing through the STEM pipeline are especially underrepresented in the field. The Americans with Disabilities Act (ADA) was signed into law 25 years ago, calling for the civil rights of individuals with disabilities and establishing expectations that schools and employers provide reasonable accommodations for people from this group. However, since the law was passed, there has not been a statistically significant increase in U.S. doctoral degrees earned in STEM fields by individuals with disabilities, despite the fact that the proportion of students interested in STEM majors upon entering college is essentially the same for students with and without disabilities [9]. As it has been shown in relation to students from other 
underrepresented groups, encouraging the participation of students with disabilities in undergraduate research experiences could bolster the pipeline of students continuing their education in STEM programs as they can gain valuable self-confidence through the experiences, begin to "think more like a scientist” [5,10,11], and shed stereotype threats. Like the United States has done through the ADA, other countries have worked to ensure the rights of individuals with disabilities. In December 2006, the United Nations adopted the Convention on the Rights of Persons with Disabilities (CRPD) to protect the rights of individuals with disabilities, including the right to inclusive education for students with disabilities [12,13]. As of 2015, 154 countries have ratified the Convention (including the European Union, China, and Switzerland) [14].

The law that established the National Technical Institute for the Deaf (NTID) at Rochester Institute of Technology (RIT) was signed 50 years ago. Through its academic programing and support services, NTID has helped numerous deaf and hard-of-hearing (d/hh) students obtain a quality postsecondary education and enter careers in their fields of choice. We describe results of our unique undergraduate research program (which involves $\mathrm{d} / \mathrm{hh}$ students, including those who are early in their college careers and those enrolled in Associate degree level programs), as well as goals and strategies for involving $\mathrm{d} / \mathrm{hh}$ students in an interdisciplinary scientific research program. It is our hope that this discussion will encourage others globally to promote undergraduate research opportunities in higher education for underrepresented students, including students with disabilities.

Though established undergraduate research initiatives, like those made possible by the National Science Foundation's (NSF) Research Experiences for Undergraduates (REU) programs, do not necessarily exclude $\mathrm{d} / \mathrm{hh}$ students from participating, most programs are composed predominantly of hearing students. The undergraduate research programs at James Madison University [15] and University of Georgia [16] were among the pioneers in broadening participation for $\mathrm{d} / \mathrm{hh}$ students in their programs. The EntryPoint program of the American Association for the Advancement of Science (AAAS) [17] has long been instrumental in helping to place $d / h$ h students in undergraduate research projects, including several years at the Center on Polymer Interfaces and Macromolecular Assemblies (CPIMA)-Summer Undergraduate Research Experience (SURE) program [18] based out of Stanford University and IBM Almaden Research Center. The American Chemical Society's (ACS) Committee on Chemists with Disabilities (CWD) has also been a champion of encouraging $\mathrm{d} / \mathrm{hh}$ students into undergraduate research settings. And at our host institution, faculty in Rochester Institute of Technology's Thomas H. Gosnell School of Life Sciences received an NSF Undergraduate Research Mentoring (URM) grant for involving $\mathrm{d} / \mathrm{hh}$ students on undergraduate research projects in the biological sciences and encouraging them to continue their education in graduate school [19].

More recently, the University of Massachusetts-Amherst [20], SUNY Stony Brook [21], and University of Delaware [22] have also made efforts to engage $d / h$ h students in higher education research laboratories, and have done so with considerable success. Dow Chemical Company has also been recognized as a leader in involving $\mathrm{d} / \mathrm{h}$ h students on research projects in an industrial setting [23]. All of the programs in this (non-exhaustive) list allow students to work in a heterogeneous (d/hh students working alongside hearing peers) communication environment. Gallaudet University, an institute devoted to the postsecondary education of $\mathrm{d} / \mathrm{hh}$ students, includes students from their academic programs in undergraduate research [24] in a more homogeneous ( $\mathrm{d} / \mathrm{hh}$ students working with other $\mathrm{d} / \mathrm{hh}$ students and signing faculty) communication environment. Though its primary mission 
is not directly related to serving large numbers of $\mathrm{d} / \mathrm{hh}$ students, Tufts University has a unique program exclusively for this population of students, and has been an exemplary program for eleven years [25].

\section{The RIT/NTID Interdisciplinary Science Undergraduate Research Program}

Our undergraduate research program is built on the same principles as other quality programs and it also involves $\mathrm{d} / \mathrm{hh}$ students, including those who are early college (students in the first two years of their college careers) and/or Associate degree level students [2]. NTID, a college of RIT, enrolls over 1400 $\mathrm{d} / \mathrm{hh}$ students and thus represents the largest technical college in the world for $\mathrm{d} / \mathrm{hh}$ students [26]. All of our research program's students, by nature of their hearing loss, belong to an underrepresented class in the field, and have consistently had a majority of female students (about 70\%). In addition, about onethird of the program's students are from traditionally underrepresented groups. The research program draws from students in the early phases of their postsecondary education who are working on Associate degrees in NTID’s Laboratory Science Technology (LST) program [27], and also those working on baccalaureate degrees in RIT's College of Science. Many of the LST students continue their involvement in the research program as they progress through baccalaureate degree programs within several of the other nine colleges of RIT.

Undergraduate research is a key initiative on the RIT campus and the research atmosphere for students and faculty alike is dynamic. Many colleges here host weekly seminars for sharing student research and Summer Undergraduate Research Fellows (SURF) programs that provide full-time support for undergraduate researchers and culminate in a large annual campus-wide symposium. Some faculty members at RIT/NTID can communicate using sign language and can have research groups comprised entirely of d/hh students (hereafter referred to as "homogenous" communication groups). In addition, RIT faculty members outside of NTID (as well as some faculty members within NTID) can have $d / h$ h students in their research laboratories working side-by side with hearing students (hereafter referred to as "heterogeneous" communication groups). These faculty members tend to know some or no sign language and can utilize a range of access resources available at RIT (sign language interpreting, C-Print \& Communication Access Real-time Translation (CART) specialists, notetakers, etc.) in order to facilitate communication within their research groups. For a detailed discussion of communication methods and aids for working with $\mathrm{d} / \mathrm{hh}$ students in the academic research laboratory, readers are encouraged to consult the reference by Smith, Ross, and Pagano [28]. It is important to note that the terms "homogenous" and "heterogeneous" communication used here are not defined strictly linguistically, as there is a large range of communication modes among $\mathrm{d} / \mathrm{hh}$ students [29,30].

\subsection{Program Objectives}

Some of the goals of our early research program were discussed by Pagano [2]. The student outcomes and benefits of the involvement of $\mathrm{d} / \mathrm{hh}$ students in our current program are listed in Table 1. The impact of positive and personalized faculty interactions with students on student success in higher education cannot be stated strongly enough. Proven especially important when working with certain underrepresented groups [31-33], these valuable interactions are likely also strong drivers in the academic and career trajectories of $\mathrm{d} / \mathrm{hh}$ students. Likewise, the resulting outcomes of these interactions can help students to establish their own identity as a competent/advanced student and as a 
scientist [34]. Involvement in undergraduate research is also valuable in correcting students' misconceptions about scientific research. Naturally, students enter the research experience with certain preconceptions, one of which is that scientific research is completed alone, while at the end of the process they become aware that the process is rarely completed in isolation [35].

Table 1. Student outcomes and benefits of involvement in undergraduate research.

- learn discipline-specific information while performing cutting-edge research

- contribute in innovative ways to the scholarship of their field

- communicate their findings with peers and professionals in their field

- take ownership of their original work

- work on projects that are logistically prohibitive in the traditional classroom setting

- learn first-hand about how research works and ethical conduct in the research setting

- be involved in experiential learning activities

- develop life-long learning skills

- apply learned course knowledge to practical projects

- be a valued member of a team as well as cultivate relationships with faculty

- gain insights into future careers and prepare for the next level of education

Of course, undergraduate research should also be mutually beneficial to faculty. Table 2 lists some of the outcomes and benefits realized by our faculty members through guiding small group or individualized research interactions with $\mathrm{d} / \mathrm{hh}$ students. Like those reported by Prunuske et al. [36], our faculty also often cite altruistic rationale and intrinsic rewards in involving undergraduate students (and especially, $d /$ hh students) in our research agendas. Watching a student grow and flourish through the research experience is especially rewarding. Nevertheless, since scholarly activity is a requirement of most higher education faculty members' plans of work, the involvement in, and progress of, these undergraduate research activities plays a practical role as well. And when faculty members feel that the different levels of administration place value on conducting undergraduate research, their job satisfaction can improve [37]. Though somewhat debated (see the review by Prince et al. [38] for a good discussion of both sides of the debate), we believe that faculty research does, in fact, improve undergraduate teaching.

Table 2. Faculty outcomes and benefits of conducting undergraduate research.

- advance their scholarly research

- integrate teaching and research efforts

- contribute to the broader aspect of students' educational plans

- provide substantial student learning opportunities while teaching beyond the time and other logistical limitations of a typical course

- promote an outlet for researchers to interact with campus peers and faculty

- cultivate relationships with students

- improve student recruitment/retention 


\subsection{Undergraduate Research with D/HH Students Who are also Early Undergraduates/Associate} Degree Level Students in the Sciences

When the term "undergraduate research" is used in higher education, most think of students at the Bachelor's degree level. However, at an Associate degree-offering institution, like NTID, undergraduate research can also refer to students at the two-year degree level. Unlike typical four-year degree programs, the focus of NTID's LST program is to facilitate the placement of students in jobs at the technician level, so hands-on, bench skills are emphasized. This program focus has been a great source of benefit to the undergraduate research environment, since these students are trained to produce data with great attention to precision and accuracy, and the results are typically of exceptional quality. We have received tremendous feedback from employers and internship/co-operative work experience supervisors of LST students/graduates in regard to their outstanding laboratory skills, attention to details, and ability to contribute to the host laboratory with minimal technical training.

There are two main barriers that make research with Associate degree level and early undergraduate researchers challenging: (1) there is a rapid turnover of undergraduate researchers-as most students complete their degree requirements within two to three years; and (2) students likely have completed minimal discipline-specific coursework (and mostly only those courses at the introductory level) prior to commencing undergraduate research projects [2]. Still, we have witnessed remarkable results from this group of students, especially when research projects are divided into manageable portions and expectations are kept clear. Students who were involved in undergraduate research during their Associate degree program may be more likely to continue in baccalaureate STEM programs. The LST program has historically had an unusually high percentage of Associate degree graduates who continue in STEM baccalaureate programs after graduation ( 70\% since the program's inception). By comparison, $\sim 90 \%$ of students in the LST program who have become involved in undergraduate research projects continue in baccalaureate degree programs.

\section{Strategies for Success in Involving D/HH Students in Scientific Undergraduate Research}

"Success" can be a generic term, ubiquitously used in higher education settings, but not always defined. Normally with undergraduate research, metrics of success might be focused primarily on publications in peer-reviewed journals, but this outcome may depend on the commitment and objectives of each individual student, faculty mentor, and project. Since there is a gap in the number of $\mathrm{d} / \mathrm{hh}$ students who enter graduate school (which is even more pronounced in the STEM fields) compared to their hearing peers, another metric could be whether or not the research student successfully enters graduate school $[39,40]$. Yet another metric of success could be whether or not the research experience has helped the student determine their career path [39]. An important indicator of the undergraduate research program's success might also include the improved recruitment and retention of students in scientific programs/degrees. Though not specifically surveying students with disabilities, several studies also showed that involvement in undergraduate research helped to retain underrepresented students in the pipeline to careers [3,8,41-43]. Again, in an effort to narrow the gap in degree attainment by $\mathrm{d} / \mathrm{hh}$ students in the sciences, we greatly value involvement in undergraduate research as a recruitment and retention tool, and have found it to be a powerful indicator of success and degree continuation. 
Though there are a few known opportunities that have been developed specifically for $\mathrm{d} / \mathrm{hh}$ students to perform undergraduate research (some of these programs were mentioned earlier), the number of such opportunities is small in comparison to those that are available to their hearing peers. We take great pride in the relatively large number of $d / h$ h students that we are able to involve in our research program. Unfortunately, at RIT/NTID we do not have a large enough critical mass of faculty or laboratory facilities to accommodate all of the $\mathrm{d} / \mathrm{hh}$ students who approach us with interest in conducting undergraduate research. An ancillary outcome of having more $\mathrm{d} / \mathrm{hh}$ students interested in the undergraduate research program than we can logistically handle is the opening of a dialogue with colleagues and working with faculty in the other colleges of RIT to find comfortable "homes" in their research laboratories for $\mathrm{d} / \mathrm{hh}$ students. We also try to be a "model” program and a "clearinghouse" of information for people outside of RIT/NTID who are interested in involving $d / h h$ undergraduate students in scientific research. We are very interested in sharing with others the high level research that these students are capable of performing.

For laboratories outside RIT/NTID, the first concern with the prospect of involving $\mathrm{d} / \mathrm{hh}$ students in scientific laboratory work often relates to safety. While a few safety concerns related to communication, laboratory procedures, and laboratory infrastructure need to be addressed (and were reviewed by Smith, Ross, and Pagano [28]), modifications to the laboratory are minor and related costs are relatively minimal. In fact, barriers to involving $d / h$ h individuals in scientific research are rarely (if ever) truly related to safety issues, but instead are often based on naiveté, unfamiliarity, or lack of experience in working with this group. In fact, the $\mathrm{d} / \mathrm{hh}$ students involved in our undergraduate research programs, as well as $\mathrm{d} / \mathrm{hh}$ professionals in the workplace, are often among the safest workers in the environment. We recognize that when working outside RIT/NTID, there are also additional logistical matters that have to be integrated, such as getting REU funding and working with the disabilities service offices for support, for example [15]. Again, these do not represent insurmountable barriers, and when they are given opportunities in research laboratories, we have found that the $d / h$ h student researchers tend to be very motivated, appreciative of the research opportunity, and extremely capable.

Pagano and Ross [44] provide a general resource for considerations in the education (chemistryspecific) of students with a variety of disabilities. Specifically at RIT/NTID, strategies that have led to successful undergraduate research experiences for both students and faculty are summarized in Table 3.

Table 3. Strategies for Successful Undergraduate Research Experiences.

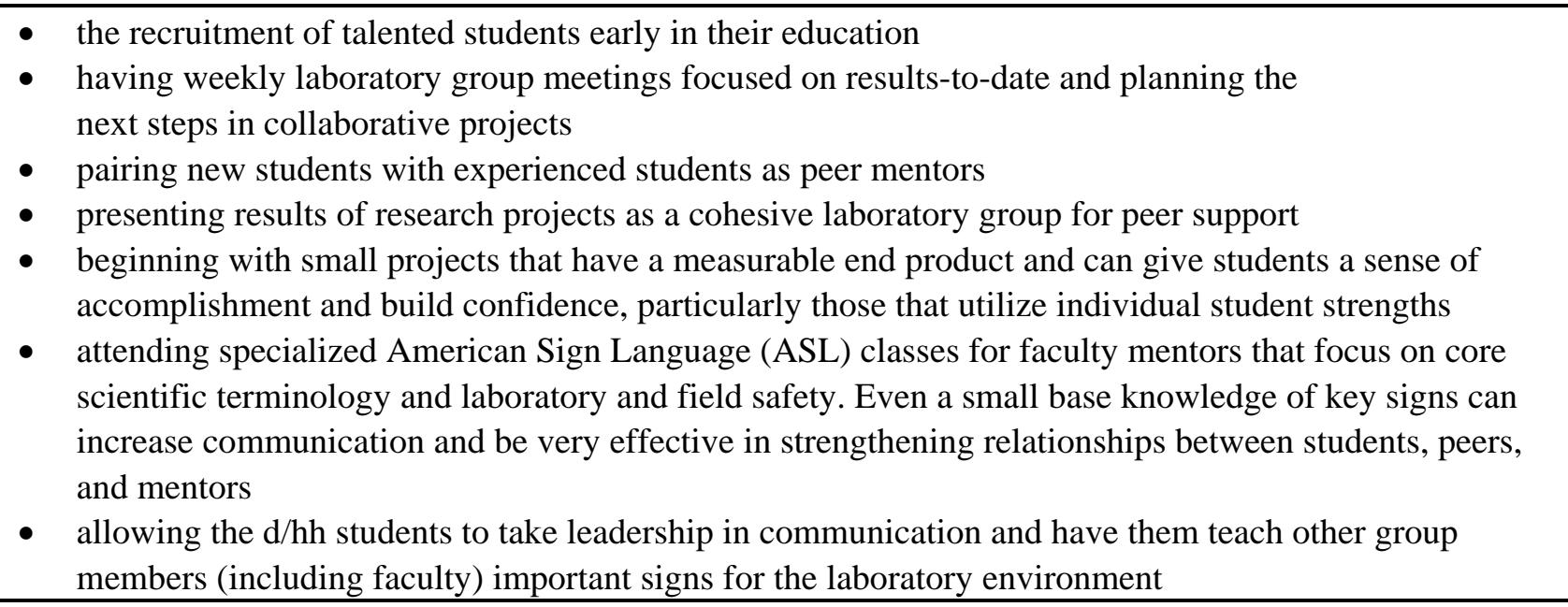




\subsection{Working with D/HH Students in a "Homogeneous" Communication Environment}

As stated, there can be homogenous and heterogeneous communication dynamics within undergraduate research group settings that involve $\mathrm{d} / \mathrm{hh}$ students. This distinction is important because communication between the mentor and the mentee (and the undergraduate researcher with his/her peers) is vital to the overall research experience. In a homogeneous laboratory group of $\mathrm{d} / \mathrm{hh}$ students, where all students (and often faculty members too) can communicate with each other, in many ways the undergraduate research environment can appear similar to any other (less the noticeable use of sign language, of course). Such situations can be very efficient and yield extremely productive results. Unfortunately, these scenarios are all too rare.

The dissemination of results from homogeneous undergraduate research groups perhaps requires the most attention. Should the student researchers want to present their findings at conferences, sign language interpreters or CART specialists would often need to be arranged for them. It is interesting to note that poster sessions have been attributed to being introduced years ago at American Chemical Society meetings, which were of great benefit to the deaf scientist Nancie Sharpless [45]. Because of her disability, she found it a better way to communicate her research findings with people one-on-one (or in small groups) [45]. Many (but not all) d/hh students do, in fact, prefer poster presentations, but in this format sign language interpreters or "communication facilitators" of some sort are often still needed. A fairly ubiquitous concern of $\mathrm{d} / \mathrm{hh}$ scientists is that interpreters and CART specialists are often not trained in the sciences, and technical jargon can get lost in either the translation of the delivery of the $\mathrm{d} / \mathrm{hh}$ researcher's presentation, or the relaying of questions from the audience to the presenter. Some feel that this can result in a misplaced notion that the presenter may not have a full grasp of understanding on the scientific topic. One way to circumvent this as best as possible (and if feasible) is to send the presentation/poster to the assigned interpreter/CART specialist ahead of time and/or meet with them prior to the presentation to go over anticipated technical terminology/jargon. It is always rewarding after one of our $\mathrm{d} / \mathrm{hh}$ students has given a presentation at a scientific symposium to see how in awe the audience can be; not only of the scientific sophistication the student portrayed, but also in how they handled the communication aspect of the presentation [2].

\subsection{Working with D/HH Students in a "Heterogeneous" Communication Environment}

RIT/NTID is rather unique in its mixed population of hearing and $d / h$ h undergraduate students in classrooms and laboratories across colleges on campus. Although multiple mechanisms are in place to provide support to $\mathrm{d} / \mathrm{h}$ h students in classroom settings, few resources are available specifically to assist with day-to-day undergraduate research mentoring in the science laboratory. In one-on-one or small-group mentoring experiences outside of RIT/NTID, hearing mentors may have little or no training in sign language and $\mathrm{d} / \mathrm{hh}$ students must often work side-by-side with hearing students on collaborative projects. Interpreting services can be made available for planned group meetings; however, the majority of laboratory and field research mentoring often takes place ad hoc, and further, troubleshooting of experimental techniques cannot always be planned ahead of time for the requesting of interpreters/CART specialists. Also, scientific terminology in new and emerging research fields may not yet have universal sign language association or recognition. As previously mentioned, many sign 
language interpreters are not specifically trained in the sciences, making many of the technical concepts unfamiliar to them. We have found that specific communication needs arise when: (1) mentors must communicate critical discipline-specific background, train students in precise techniques and new protocols, and troubleshoot results and data analyses; (2) d/hh students train, or are trained by, hearing students and share tasks on research projects; and (3) technicians, external research collaborators, and graduate students train and assist undergraduates in the laboratory and field. In these situations, group members must be guided through creative modes of communicating and teaching. Some of the communication mechanisms include simpler techniques like using the texting feature with cellular phones, to more costly methods like video remote interpreting (VRI)—where an $\mathrm{iPad} /$ smartphone can connect with a video relay interpreter that appears on screen. NTID offers a program, "Working Together” [46], where staff/faculty from NTID can visit an organization that is new to hosting $\mathrm{d} / \mathrm{hh}$ students (for example as summer interns) in order to discuss the logistics of working/interacting in the general workplace. Strategies and best practices for working with $d / h h$ students specifically in the science laboratory were discussed by Smith, Ross, and Pagano [28].

Though initial safety and communication concerns may arise in the undergraduate research laboratory, we have observed that these challenges are quickly dissipated and the result is often a richer, more productive experience for both $\mathrm{d} / \mathrm{hh}$ and hearing students alike. In fact, we argue that the experience is quite enriching for the faculty mentor as well. A great way to show the reciprocity in learning in higher education (i.e., that the professor can also learn from the students) is to let the $\mathrm{d} / \mathrm{hh}$ student take the lead in the communication process, allowing them to teach the faculty member (and the research group) new signs and take the initiative in demonstrating new avenues of communication. It is important to remember that in many cases the $\mathrm{d} / \mathrm{hh}$ students have been living with the hearing loss their entire life (or for a large portion of their life) and they have developed competent skills in finding ways to communicate with hearing peers.

The opportunity for a $\mathrm{d} / \mathrm{hh}$ student to work directly with hearing collaborators and more senior research students ( $\mathrm{d} / \mathrm{hh}$ or hearing) can be a powerful mentoring tool, often bridging gaps in social and academic units on campus, and external work environments. These integrated research experiences can also have tremendous value to hearing research colleagues and collaborators. Mentors often feel that they have thought more deeply about project areas that need clarification and find that working in these integrated settings stimulates a creative perspective on their teaching and mentoring for all students. Hearing research students gain valuable experience in communicating their projects/results in different formats to a variety of audiences, and this often leaves them with a deeper understanding of their research and more comfort with the dissemination to the broader scientific community. Overall, these integrated learning and mentoring environments leave students, both $\mathrm{d} / \mathrm{hh}$ and hearing, with a unique research experience and a more diverse skillset that can promote their future career endeavors in the science fields. Positive things happen with diversity and when people with varying backgrounds and experiences work together and link minds. 


\subsection{Strategies for Involving Early Undergraduate/Associate Degree Level D/HH Students in} Scientific Research

There is little argument that higher education programs with graduate students are primed for conducting research. For programs without graduate students (and even for some of those with), the current buzz in academic research is largely undergraduate research, typically at the baccalaureate degree level. Probably true across disciplines, but especially true in the physical and natural sciences, research opportunities are often scarce for students studying at the Associate degree level. While much has been written in the literature about strategies for mentoring graduate and baccalaureate students, less attention has been given to involving students at the Associate degree level in the chemical and biological sciences. However, recognition of research activities at this level has grown, and has been valued by organizations like the Council on Undergraduate Research (CUR) [47] and the American Nurses Association, which published guidelines for including Associate degree level nurses in undergraduate research [48].

Early career undergraduate students and students enrolled in Associate degree programs can find success with undergraduate research if faculty can find ways to provide them with these valuable experiences. At this level, it is critical that faculty mentors break the research projects into manageable portions that have obtainable checkpoints along the way, as well as a defined endpoint. To avoid students in such situations from feeling "fragmented" or not connected to the rest of the research, group meetings are a great way for students to see how their contributions to the research relate to the larger picture of the research group's initiatives. Furthermore, projects need to be designed for the students at this level that match their ability at the time of their involvement in the research project. This is not to say that the projects need to be "watered down", but assigning a highly advanced, open-ended, or theoretical project might not yield optimal success for this subset of researchers. Similarly, if portions of these higher-level projects can be divided into manageable projects, student success will likely increase. Faculty mentors may also need to address the more conceptually difficult portions of the research by teaching certain scientific concepts to the student (prior to the students taking the coursework where such concepts would typically be covered). Finally, establishing peer mentoring relationships can also allow more experienced group members to help guide newer undergraduate researchers.

Logistics in the design and conduct of the research may be more challenging and require some creative thinking when involving early undergraduate students. Faculty members who advise Associate degree level student researchers are well aware of the fact that student turnover is high as they transfer to four-year programs or to the workplace. Nevertheless, the $d / h$ h students at NTID have produced some of the best data that has been collected under our lead. This is in large part due to the pride these students take in their skillset and their gratitude for being granted such a rare opportunity to participate in original scientific research. We encourage faculty mentors to cast aside pre-conceived notions about ability and work to involve early undergraduates and Associate level $\mathrm{d} / \mathrm{hh}$ students in their research initiatives. 


\subsection{Mechanisms for Disseminating the Results of Undergraduate Research Projects}

The dissemination of performed scholarship and research results in higher education is vital. Students are very important in this stage of the scholarship process as well. Though publication in peer-reviewed journals may be the "gold standard" for the culmination and dissemination of a successful research study, with undergraduate researchers, conference presentations also represent great opportunities for students to develop skills in technical communication of their research initiatives to professional audiences. Conference presentations can also be a vehicle for students to feel that they are more a part of the scientific community [49]. We are proud that over the lifetime of our research program, we have had over fifty $\mathrm{d} / \mathrm{hh}$ research students present at over twenty-five different local and national conferences. When out of town travel is required, we obtain funding for the students' travel expenses through different avenues, including working closely with our Development and Alumni Relations departments to help secure donations to make the conference travel possible. Especially with early undergraduate students, presentations need not always be at professional societies, as campus events can be a great avenue for students to hone their presentation skills while making the research more visible to other students, colleagues, administrators, and external visiting publics. We have had opportunities to showcase our research at meetings of RIT's Board of Trustees, RIT/NTID alumni, NTID’s National Advisory Group, and NTID’s Foundation Board. Presentations to Trustees and advisory groups can have the ancillary benefit of giving the student a venue to present the results of his/her research while also demonstrating the value of undergraduate research to those responsible for guiding the institute's policies and initiatives (which can return in the form of the institute's greater value of undergraduate research). For three consecutive years, we were very proud when three of our d/hh Associate degree-level research students won the award for best research presentation at RIT's annual Undergraduate Research Symposium.

Despite the dynamic and interactive atmosphere of research presentations, we still value publication of results in primary literature, and some projects from which the research initiatives yielded peer-reviewed journal publication are listed below. The successful dissemination of research results can be a rewarding capstone to a successful undergraduate research project and tends to generate a great sense of pride, ownership, and accomplishment in their research by the students [2].

\section{Examples Undergraduate Research Projects in the RIT/NTID Program}

The following are brief summaries of the chemical and biological research projects in which our students have been, or currently are, involved. These projects have proven to be of an appropriate level for early undergraduates and have been deemed interesting enough by the students to keep their interest in the conduct of the research. Most of the projects have interdisciplinary and environmental applications, thus taking advantage of students' innate care and curiosity about the environment and sustainability issues. Students were involved in the dissemination process as well—by contributing to, or often being co-authors of, the referenced articles. 


\subsection{Fruit Nutrition for Migratory Birds [50]}

Seasonal wild fruits are an important food resource for migratory songbirds in eastern North America during autumn (representative species are shown in Figure 1), as birds replenish the energy reserves needed to continue migration [51]. This project aims to assess the nutritional and biochemical components of wild fruits as they relate to the health and condition of birds that consume them. Recent research suggests that the fruits of invasive shrubs are of lower nutritional value to birds than the fruits of native shrubs during autumn migration [50]. Our project builds upon this research to explore antioxidant and other biochemical properties of native and invasive fruits, and annual differences in fruit quality in an effort to assess the future impacts of emerging threats to migratory birds, namely the spread of invasive fruit-bearing plants and climate change. We are also exploring a novel nutritional "fingerprinting" technique using multidimensional fluorescence spectroscopy coupled with chemometric analysis to characterize fruit species and assess differences in the biochemical make-up of fruits across seasons. This project was conducted in a heterogeneous communication environment by students in RIT's College of Science.

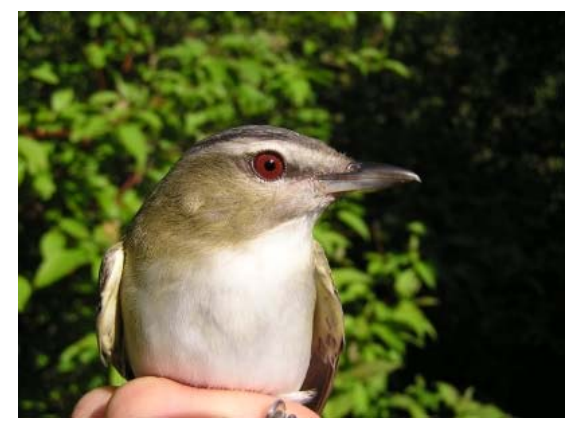

(a)

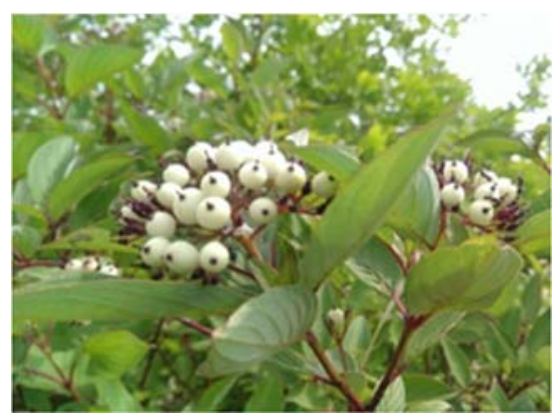

(b)

Figure 1. (a) Red Eyed Vireo (Vireo olivaceus); (b) Red Osier Dogwood (Cornus sericea) berries analyzed as part of a study of the nutritional quality of fruits consumed by migratory birds.

\subsection{Polyaromatic Hydrocarbon Analysis of Cigarette Smoke}

The identification and quantification of carcinogenic agents from cigarette smoke in the lungs is crucial to an understanding of smoking induced lung cancer. In this project, polyaromatic hydrocarbon (PAH) byproducts of the smoking process are collected from an artificial lung using an in-house engineered smoking machine. The samples are analyzed by Gas Chromatography-Mass Spectrometry (GC-MS). Qualitative and quantitative analyses uncover vital information about the fate and transport of certain PAHs in the lung system. A chromatogram of the target PAH carcinogens in a reference cigarette is shown in Figure 2. This project has a focused impact, as the knowledge gained in the model lung system will augment our understanding about the deposition of potential carcinogens in the human lung. These results will give us a better understanding of the composition and location of carcinogens that might cause lung cancer. This project was conducted in a homogeneous communication environment by students in the LST program. 


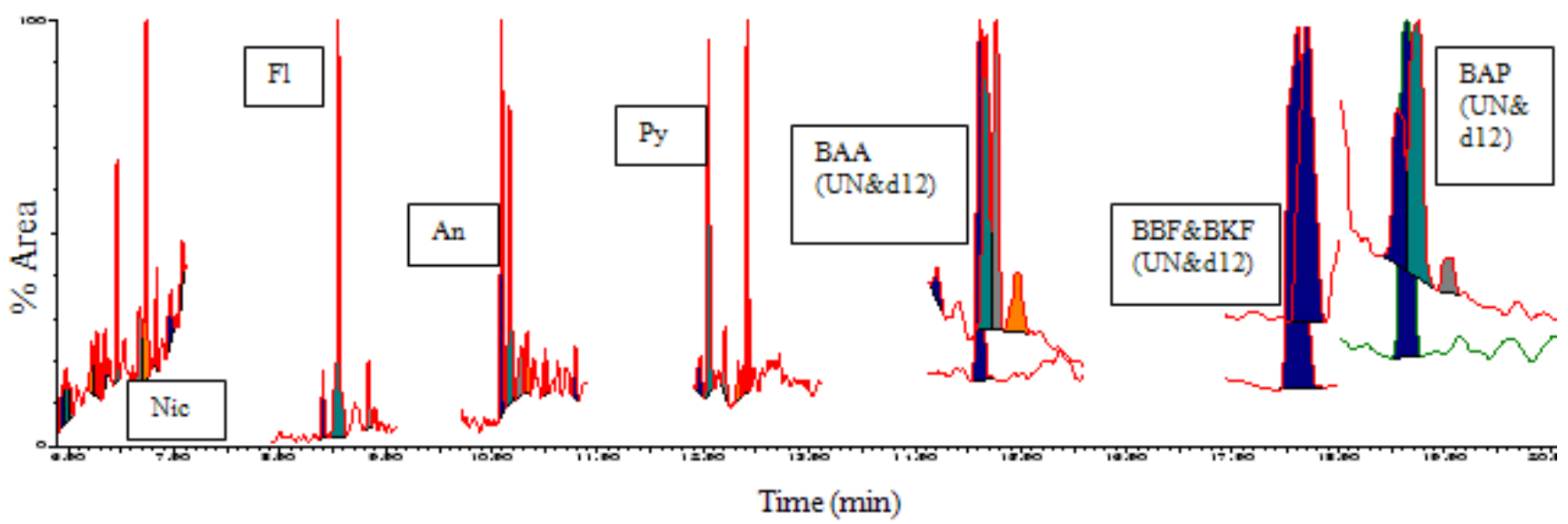

Figure 2. Chromatogram of a Kentucky Reference cigarette, 3R4F. The molecules of interest are nicotine [Nic], fluorene [Fl], anthracene [An], pyrene [Py], Benzo[a]anthracene [BAA UN], Benzo[b] fluoranthene [BBF UN], Benzo[k] fluoranthene [BKF UN], and Benzo[a] pyrene [BAP UN]). Peaks for the deuterated surrogates [d12] are shown beside their corresponding analytes. Colored areas under peaks represent the peak’s integration.

\subsection{Isolation, Identification, and Quantification of Active Ingredients in the Essential Oil of Nutmeg}

This project involves the study of bioactive molecules extracted from natural products. Isoeugenol, an active component of the essential oil of nutmeg, was identified, quantified, and biologically tested. High Performance Liquid Chromatography (HPLC), Gas Chromatography (GC), and Fourier Transform Infrared Spectroscopy (FTIR) were used to identify and quantify isoeugenol in the essential oil of nutmeg. Isoeugenol was determined to compose approximately $1 \%$ of the total essential oil profile, and it was also found to have antioxidant and antibiotic properties, as its biological activity was assessed in a sensitivity test to the bacteria, Bacillus cereus. Planned future work into the analytical characterization of the essential oil of nutmeg, its sensitivity tests to other bacteria, and its applicability as a natural pesticide is addressed. These results and future experiments may support speculative insights into the historical impact of nutmeg as a deterrent against the Black Plague. This project was conducted in both homogeneous and heterogeneous communication environments by students in the LST program and students in RIT's College of Science.

\subsection{Development of a Novel Instrument for the Simultaneous Detection of Parameters for the "Unveiling” of Fluorescence Spectra [52]}

This research project aims to explore issues of spectroscopic photophysical interest (fluorescence quenching and energy transfer) using an engineering-based approach to the instrument development. The instrument, built at RIT/NTID, uses a variety of light sources, spectrometers, and fiber-optics in order to perform complex analyses. It can simultaneously measure steady-state fluorescence, fluorescence lifetime, absorbance, and oxygen concentration so that valuable chemical, physical, and temporal information can be obtained in real-time. Discrete relationships can be drawn between the occurring fluorescence quenching phenomena (represented in Figure 3). This technique can be applied to a 
variety of samples, including those of environmental, biological, and industrial importance. This project was conducted in a homogeneous communication environment by students in the LST program.

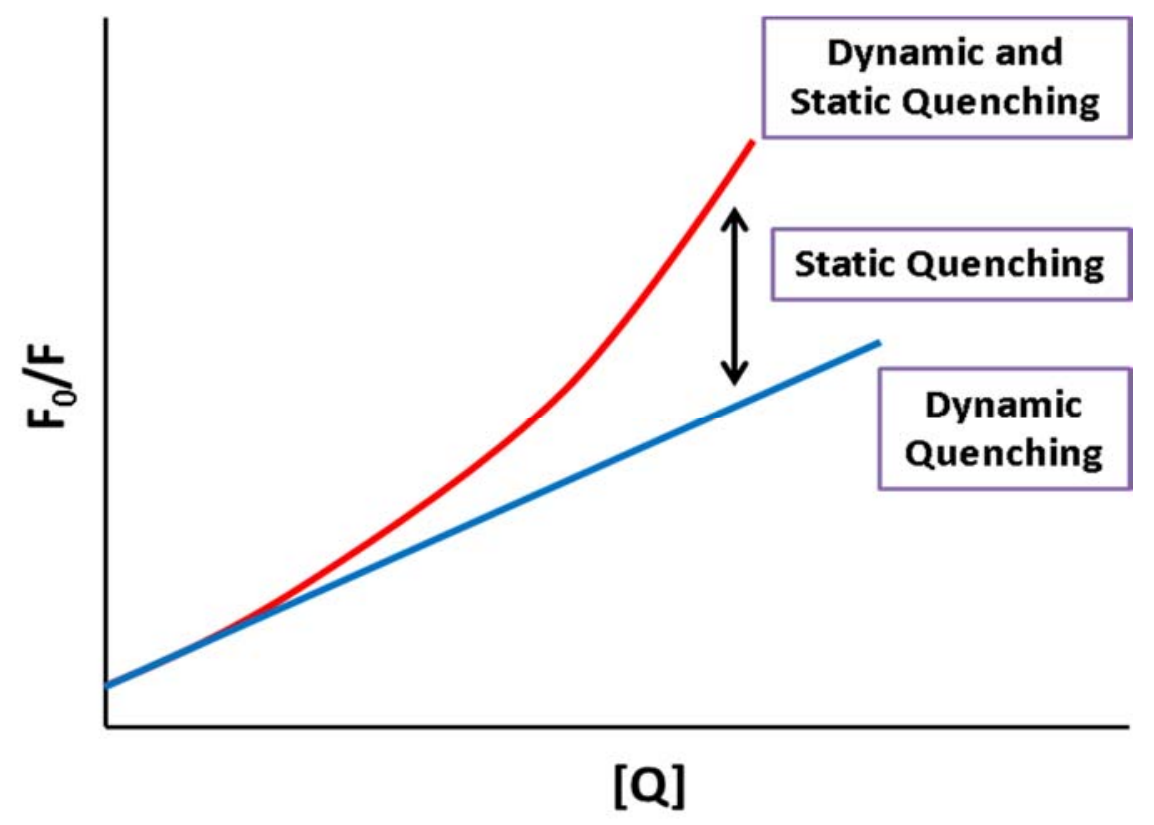

Figure 3. Stern-Volmer Plot showing the different forms of fluorescence quenching by a quencher, Q, that are uncovered using the novel instrumental set-up for the simultaneous measurement of important spectroscopic data.

\subsection{Intermolecular Energy Transfer in Fluorescence Spectroscopy [53]}

Due largely to its sensitivity, fluorescence spectroscopy is a popular choice for the measurement of certain molecules. However, for proper analysis, energy transfer mechanisms (namely, inner filtering and oxygen quenching) that inhibit fluorescence signals must be understood and taken into account. The concealing of molecular fluorescence spectra due to inner filter effects, and the techniques used to correct collected spectra for inner filtering, have been studied, and their impact on fluorescence spectra are represented in Figure 4. The impact of oxygen quenching on collected fluorescence spectra and purging procedures for the deoxygenation of solutions have also been studied and quantified. The impact of this work is the gaining of a photophysical understanding of some of the phenomena that mask fluorescence results, and therefore limit the utility of fluorescence spectroscopy in some circumstances. Since fluorescence spectroscopy is a powerful tool for analysis in many different fields (from environmental to medical), the understanding of these phenomena should improve the utility of fluorescence spectroscopy across many disciplines. This project was conducted in a homogeneous communication environment by students in the LST program. 


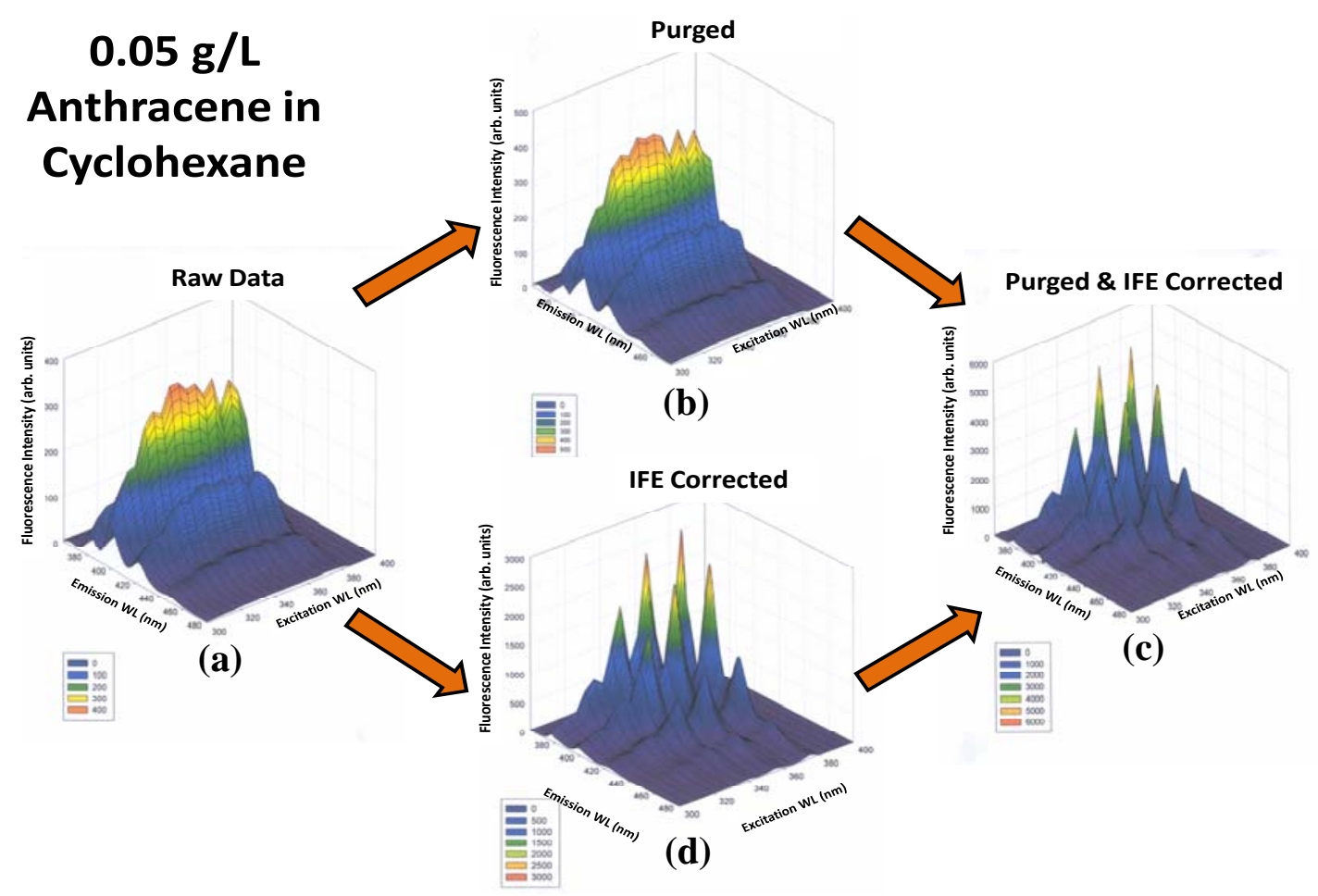

Figure 4. Fluorescence Excitation-Emission Matrices showing the impact of oxygen quenching (b), inner filter effects (d), and combined quenching and inner filtering (c) on the raw spectrum of anthracene in cyclohexane (a).

\subsection{Dissolved Organic Matter in Natural Waters [54]}

Wetlands play an important role in the production and transformation of watershed-derived dissolved organic matter (DOM). Indicators suggest the amount of wetlands' DOM has been increasing for several decades. Climate change has been proposed as a potential contributor to the trend, and under this mechanism the phenolic content of DOM may be experiencing a disproportionally large increase [55]. We explored the possibility of assessing the phenolic character of DOM using multidimensional fluorescence spectroscopy as a more convenient alternative to "wet chemistry" methods. In this work, parallel factor analysis (PARAFAC) was applied to fluorescence excitation-emission matrices (EEMs) of humic samples, in an attempt to analyze their phenolics. PARAFAC results were correlated with phenol concentrations derived from the Folin-Ciocalteau reagent-based method. The reagent-based method showed that the phenolic content of five International Humic Substance Society (IHSS) DOM samples varied significantly in phenol concentration. Results of the study show the potential for PARAFAC analysis of multidimensional fluorescence data to be a tool for monitoring phenolics in DOM. Applications include assessing the potential for the formation of disinfection byproducts upon chlorination/treatment of drinking water sources, and monitoring the impact of Climate Change on the phenolic character of DOM. This project was conducted in a homogeneous communication environment by students in the LST program and students in RIT's College of Science. 


\section{Conclusions}

Based on our experiences, we have found our undergraduate research program to be successful, in part, because of the following key components: (1) the availability of interesting/desirable research projects; (2) a research team consisting of like-minded peer students; and (3) dedicated faculty members that are willing to provide individualized and small-group attention to the undergraduate researchers. Interesting projects are necessary because if students are not intrigued by these projects, their level of involvement may be lacking, contributing to a higher participant turnover rate. While providing these research opportunities is not an easy task, the commitment of dedicated and talented faculty leading the research team is the driver for establishing and sustaining effective programs. The aforementioned faculty members also need to take the time to carefully plan projects that are divided into manageable portions and to work with the undergraduate researchers to demonstrate how the smaller projects can relate to the overall research objectives of the group. Faculty members often work under extreme time constraints, so it can be challenging to fit these valuable interactions in faculty schedules. The above scientific projects represent successful and high-level interdisciplinary examples that have proven interesting to the students, have been conducted at a level that helped to dictate student success, and have underlying scientific merit worthy of dissemination/publication.

Communication in research groups that involve $\mathrm{d} / \mathrm{hh}$ undergraduate students requires some forethought and flexibility. Approaches to ensuring success can vary with group dynamics, and different strategies can be employed in homogeneous or heterogeneous communication group settings. That said, communication is not an absolute barrier to including $\mathrm{d} / \mathrm{hh}$ undergraduates in research, nor is laboratory safety (as those concerns can be readily remedied). Instead, when faculty members and their research groups are willing to open their laboratories, great collaboration can occur and people from different backgrounds can learn from each other. Adding diversity and increasing inclusion in this way can create a fuller, richer experience for everyone involved in the research group. Greater social and attitudinal gains of the research group will likely be observed, as will new and effective approaches to scientific problem solving that arise from the sharing of ideas/strategies among people with different experiences and perspectives.

Through the undergraduate research process, students begin to become encultured into the fields of science and gain self-confidence-outcomes that are especially valuable to underrepresented students. Though still underrepresented in the fields of science, today $\mathrm{d} / \mathrm{hh}$ students are involved in cutting-edge research, and graduates of higher education programs are performing work as valued members of distinguished laboratories. If this momentum can continue (or even accelerate), the STEM pipeline that is currently "leaking” potentially skilled students with disabilities can be improved, resulting in greater numbers of these individuals who obtain higher education STEM degrees and careers. We hope that this discussion encourages faculty members around the world to broaden the participation of $\mathrm{d} / \mathrm{hh}$ individuals in their undergraduate research laboratories, and eventually pave the way for the hiring of these remarkable individuals into scientific careers. 


\section{Acknowledgments}

This work is all about the extraordinary students who have been involved in our undergraduate research program. The above student projects were funded in part by various agencies, including the National Science Foundation (\#DBI-0829259), American Cancer Society (\#RSG-05-021-01-CNE), Ocean Optics (Educational Grant, Program B), Camille \& Henry Dreyfus Foundation funds in support of the ACS Award for Encouraging Disadvantaged Students into Careers in the Chemical Sciences (awarded to T.P.), NTID’s Innovations Grant, RIT's College of Science Faculty Education and Development grant, and the American Wildlife Conservation Foundation Grant Program. The content of this article is solely the responsibility of the authors and does not necessarily represent the official views of the supporting agencies/organizations.

This article is dedicated to the visionaries who created NTID and to its current President, Gerry Buckley, on the occasion of the 50th Anniversary of the signing of the law to establish NTID by President Lyndon Baines Johnson.

\section{Author Contributions}

The authors contributed equally to this work.

\section{Conflicts of Interest}

The authors declare no conflict of interest.

\section{References}

1. Miller, R.L.; Rycek, R.F.; Fritson, K. The effects of high impact learning experiences on student engagement. In 3rd World Conference on Educational Sciences (2011); Elsevier Science Bv: Amsterdam, The Netherlands, 2011; Volume 15.

2. Pagano, T. Conducting Research with Early Undergraduate Students and Students with Special Needs. In Broadening Participation in Undergraduate Research: Fostering Excellence and Enhancing the Impact; Council on Undergraduate Research (CUR): Washington, DC, USA, 2009.

3. Jones, M.T.; Barlow, A.E.; Villarejo, M. Importance of undergraduate research for minority persistence and achievement in biology. J. High. Educ. 2010, 81, 82-115.

4. Marginson, S.; Tytler, R.; Freeman, B.; Roberts, K. STEM: Country Comparisons: International Comparisons of Science, Technology, Engineering and Mathematics (STEM) Education. Final Report; Australian Council of Learned Academies: Melbourne, Australian, 2013.

5. Hurtado, S.; Cabrera, N.L.; Lin, M.H.; Arellano, L.; Espinosa, L.L. Diversifying Science: Underrepresented Student Experiences in Structured Research Programs. Res. High. Educ. 2009, 50, 189-214.

6. Dowling, C.B.; Hannigan, R.E. Developing cohorts, Fostering Retention, and Nuturing Careers. In Broadening Participation in Undergraduate Research: Fostering Excellence and Enhancing the Impact; Council on Undergraduate Research (CUR): Washington, DC, USA, 2009; pp. 219-222.

7. Coronado, G.D.; Shuster, M.; Ulrich, A.; Anderson, J.; Loest, H. Strategies for Diversifying the Pool of Graduate Students in Biomedical Sciences. J. Cancer Educ. 2012, 27, 436-442. 
8. Lopatto, D. Undergraduate research experiences support science career decisions and active learning. CBE-Life Sci. Educ. 2007, 6, 297-306.

9. Booksh, K.; Century, J.; Gallagher, J.; Mateo, J.; Pagano, T. On the Sustainability of Programs for Students with Disabilities: Observations and Practical Ideas. In From College to Careers: Fostering Inclusion of Persons with Disabilities in STEM; Duerstock, B., Shingledecker, C., Eds.; AAAS Custom Publishing Office: Washington, DC, USA, 2014; p. 61.

10. Hunter, A.-B.; Laursen, S.L.; Seymour, E. Becoming a scientist: The role of undergraduate research in students' cognitive, personal, and professional development. Sci. Educ. 2007, 91, 36-74.

11. Seymour, E.; Hunter, A.-B.; Laursen, S.L.; Deatoni, T. Establishing the benefits of research experiences for undergraduates in the sciences: First findings from a three-year study. Sci. Educ. 2004, 88, 493-534.

12. United Nations. Convention on the Rights of Persons with Disabilities. Available online: http://www.un.org/disabilities/convention/conventionfull.shtml (accessed on 5 May 2015).

13. Kanter, A.S.; Damiani, M.L.; Ferri, B.A. The Right to Inclusive Education under International Law: Following Italy’s Lead. J. Spec. Needs Educ. 2014, 17, 21-31.

14. United Nations. The United Nations Programme on Disabilities. Available online: http://www.un.org/disabilities/ (accessed on 6 May 2015).

15. MacDonald, G. Integrating Interpreting, Hearing, and Deaf Students in Summer Research. In Broadening Participation in Undergraduate Research: Fostering Excellence and Enhancing the Impact; Boyd, M.K., Wesemann, J.L., Eds.; Council on Undergraduate Research (CUR): Washington, DC, USA, 2009.

16. Starai, V.; Downs, D. Research Experiences for Undergraduates (REU) Sites. Available online: http://www.nsf.gov/awardsearch/showAward?AWD_ID=1062589 (accessed on 29 March 2015).

17. American Association for the Advancement of Science Project on Science, Technology and Disability: Entry Point for Students. Available online: http://ehrweb01.aaas.org/entrypoint/epstudents/ (accessed on 29 March 2015).

18. Frank, C.W. Center on Polymer Interfaces and Macromolecular Assemblies (CPIMA)-Summer Undergraduate Research Experience (SURE) Program. Available online: http://cpima.stanford. edu/education/sure-program-reu/ (accessed on 29 March 2015).

19. Sweet, H.; Newman, D. The RIT Undergraduate Research Diversity Initiative: Increasing Participation of Deaf and AALANA Students in the Research Scholars Program. Available online: http://nsf.gov/awardsearch/showAward?AWD_ID=0829259 (accessed on 29 March 2015).

20. Bhatia, S. NSF REU Site. Available online: http://www.nsf.gov/awardsearch/ showAward?AWD_ID=1005083 (accessed on 29 March 2015).

21. Bhatia, S. Stony Brook Chemistry REU. Available online: https://sites.google.com/a/stonybrook. edu/chemreu/ (accessed on 19 March 2015).

22. Booksh, K. Research Experience for Undergraduates Science and Engineering Leadership Initiative (SELI). Available online: http://www.chem.udel.edu/research-experience (accessed on 29 March 2015).

23. Hu, J. Two Deaf Interns at Dow Offering New Perspective. Available online: http://articles.philly.com/2011-08-07/business/29861582_1_sign-language-hearing-and-deafworlds-finger-spelling (accessed on 29 March 2015). 
24. Solomon, C. Gallaudet Receives Maryland Sea Grant Award. Available online: http://www.gallaudet.edu/daily_digest/maryland_sea_grant_award.html (accessed on 29 March 2015).

25. Cebe, P. Taking a Team Approach in an Internship Program for Deaf and Hard-of-Hearing Undergraduate Students. In Broadening Participation in Undergraduate Research: Fostering Excellence and Enhancing the Impact; Council on Undergraduate Research (CUR): Washington, DC, USA, 2009.

26. National Technical Institute for the Deaf (NTID). NTID 2013 Annual Report; NTID: Rochester, NY, USA, 2013; p. 5.

27. Pagano, T.; Ross, A.D. A Program like any other...like none other: Sustaining a laboratory science technology program for deaf and hard-of-hearing students. J. Sci. Educ. Stud. Disabil. 2010, 15, 11-15.

28. Smith, S.B.; Ross, A.D.; Pagano, T. Chemical and Biological Research with Deaf and Hard-ofHearing Individuals: Ensuring a Safe and Successful laboratory Environment. J. Chem. Health Saf. 2015, doi:10.1016/j.jchas.2015.03.002.

29. Knoors, H.; Marschark, M. Language planning for the 21st century: Revisiting Bilingual Language Policy for Deaf Children. J. Deaf Stud. Deaf Educ. 2012, 17, 291-305.

30. Knoors, H.; Marschark, M. Teaching Deaf Learners: Psychological and Developmental Foundations; Oxford University Press: New York, NY, USA, 2014.

31. Hurtado, S.; Eagan, M.K.; Tran, M.C.; Newman, C.B.; Chang, M.J.; Velasco, P. "We Do Science Here": Underrepresented Students' Interactions with Faculty in Different College Contexts. J. Soc. Issues 2011, 67, 553-579.

32. Thiry, H.; Laursen, S.L. The Role of Student-Advisor Interactions in Apprenticing Undergraduate Researchers into a Scientific Community of Practice. J. Sci. Educ. Technol. 2011, 20, 771-784.

33. Cole, D. Do interracial interactions matter? An examination of student-faculty contact and intellectual self-concept. J. High. Educ. 2007, 78, 248-272.

34. Thiry, H. What Experiences Help Students Become Scientists? A Comparative Study of Research and Other Sources of Personal and Professional Gains for STEM Undergraduates. J. High. Educ. 2011, 82, 357-388.

35. Cartrette, D.P.; Melroe-Lehrman, B.M. Describing Changes in Undergraduate Students' Preconceptions of Research Activities. Res. Sci. Educ. 2012, 42, 1073-1100.

36. Prunuske, A.J.; Wilson, J.; Walls, M.; Clarke, B. Experiences of Mentors Training Underrepresented Undergraduates in the Research Laboratory. Cell Biol. Educ. 2013, 12, 403-409.

37. Webber, K.L.; Nelson Laird, T.F.; BrckaLorenz, A.M. Student and Faculty Member Engagement in Undergraduate Research. Res. High. Educ. 2013, 54, 227-249.

38. Prince, M.J.; Felder, R.M.; Brent, R. Does Faculty Research Improve Undergraduate Teaching? An Analysis of Existing and Potential Synergie. J. Eng. Educ. 2007, 96, 283-294.

39. Smith, O.L.; Dragojlovic, V. A Design of an Undergraduate Research Program in Chemistry. J. Lab. Chem. Educ. 2013, 1, 25-33.

40. Eagan, M.K.; Hurtado, S.; Chang, M.J.; Garcia, G.A.; Herrera, F.A.; Garibay, J.C. Making a Difference in Science Education: The Impact of Undergraduate Research Programs. Am. Educ. Res. J. 2013, 50, 683-713. 
41. Villarejo, M.; Barlow, A.E.; Kogan, D.; Veazey, B.D.; Sweeney, J.K. Encouraging Minority Undergraduates to Choose Science Careers: Career Paths Survey Results. CBE-Life Sci. Educ. 2008, 7, 394-409.

42. Schwartz, J. Faculty as Undergraduate Research Mentors for Students of Color: Taking into Account the Costs. Sci. Educ. 2012, 96, 527-542.

43. Kinkead, J. Learning through Inquiry: An Overview of Undergraduate Research. New Dir. Teach. Learn. 2003, 93, 5-17.

44. Pagano, T.; Ross, A. Teaching Chemistry to Students with Disabilities, 4.1 ed.; American Chemical Society Committee on Chemists with Disabilities: Washington, DC, USA, 2015.

45. Lang, H.G. Silence of the Spheres: The Deaf Experience in the History of Science; Bergin \& Garvey: Westport, CT, USA, 1994.

46. National Technical Institute for the Deaf Working Together: Deaf and Hearing People, A Workshop for Employers. Available online: http://www.ntid.rit.edu/nce/employers/workingtogether-workshop (accessed on 5 May 2015).

47. Boyd, M.K.; Wesemann, J.L.; Frederick, K.A.; Broadening Participation in Undergraduate Research: Fostering Excellence and Enhancing the Impact; CUR (Council on Undergraduate Research): Washington, DC, USA, 2009.

48. Ayers, D.M.M.; Coeling, H. Incorporating Research into Associate Degree Nursing Curricula. J. Nurs. Educ. 2005, 44, 515-518.

49. Mabrouk, P.A. Survey Study Investigating the Significance of Conference Participation to Undergraduate Research Students. J. Chem. Educ. 2009, 86, 1335.

50. Smith, S.B.; deSando, S.A.; Pagano, T. Value of Native and Invasive Fruit-Bearing Shrubs for Migrating Songbirds. Northeast. Nat. 2013, 20, 171-184.

51. Smith, S.B. A Physiological Assessment of Seasonal Differences in Spring and Autumn Migration Stopover at Braddock Bay, Lake Ontario. Condor 2013, 115, 273-279.

52. Pagano, T.; Carcamo, N.; Kenny, J.E. Investigation of the Fluorescence Quenching of 1-Aminoanthracene by Dissolved Oxygen in Cyclohexane. J. Phys. Chem. A 2014, 118, 11512-11520.

53. Pagano, T.; Biacchi, A.J.; Kenny, J.E. Nitrogen gas purging for the deoxygenation of polyaromatic hydrocarbon solutions in cyclohexane for routine fluorescence analysis. Appl. Spectrosc. 2008, 62, 333-336.

54. Pagano, T.; Ross, A.; Chiarelli, J.; Kenny, J.E. Multidimensional Fluorescence Studies of the Phenolic Content of Dissolved Organic Carbon in Humic Substances. J. Environ. Monit. 2012, 14, 937-943.

55. Pagano, T.; Bida, M.; Kenny, J.E. Trends in Levels of Allochthonous Dissolved Organic Carbon in Natural Water: A Review of Potential Mechanisms under a Changing Climate. Water 2014, 6, 2862-2897.

(C) 2015 by the authors; licensee MDPI, Basel, Switzerland. This article is an open access article distributed under the terms and conditions of the Creative Commons Attribution license (http://creativecommons.org/licenses/by/4.0/). 